\title{
O ERUV NA EUROPA, NOS ESTADOS UNIDOS E NO BRASIL: NOVAS ESTRATÉGIAS DE DEMARCAÇÃO DO ESPAÇO JUDAICO
}

\author{
Marta Francisca Topel*
}

It's like social engineering.... We [the Jewish people] fought like hell to get out of the ghetto, and now they want to create that again.

\section{Resumo}

(Arnold Sheiffer $)^{1}$

No artigo são discutidas as mudanças acontecidas nas comunidades da diaspóra nas últimas décadas no que diz respeito a novas estratégias de apropriação do espaço público. Para ilustrar esta questão, são analisadas as controvérsias suscitadas em cidades dos Estados Unidos e da Inglaterra como resultado do estabelecimento de eruvim em alguns de seus bairros. Finalmente, tendo como base empírica os bairros judaicos paulistanos, tentou-se mostrar como eles também estão passando por um processo de judaização, que inclui diferentes modos de apropriação do espaço público pelas correntes ortodoxas da cidade.

Palavras-chave: Judaísmo, representações espaciais, diáspora, identidade étnico-religiosa, ortodoxia

\section{Abstract}

In the present paper, the author discusses the changes undergone by the diasporic Jewish communities over the last few decades regarding new strategies for the appropriation of public space. To illustrate this question, the author has analyzed controversies occurred in American and British cities and towns as a result of the establishment of eruvim in certain neighborhoods. Finally, empirically considering the so-called Jewish neighborhoods of Sao Paulo, this work intends to demonstrate the way these are equally undergoing a process of

* Antropóloga, professora e pesquisadora no Programa de Língua Hebraica, Literatura e Cultura Judaicas da Faculdade de Filosofia, Letras e Ciências Humanas, da Universidade de São Paulo.<mftopel@usp.br> 
Judaization, which features distinct modes of appropriation of public space by the Orthodox movements in the city.

Keywords: Judaism, spatial representations, diaspora, ethnic-religious identity, orthodoxy

\section{Novas estratégias de inserção nas diásporas judaicas: o re- nascimento do gueto e a visibilidade dos judeus na sociedade contemporânea}

as últimas três décadas, as comunidades da diáspora (nos Estados Unidos,
na Europa, na África do Sul e na América Latina) desenvolveram novos modos de inserção nas respectivas sociedades hospedeiras. A mudança radica, basicamente, na maior visibilidade de segmentos importantes dessas comunidades e na apropriação do espaço local, com o qual existe uma identificação tão grande que permite marcá-lo e torná-lo próprio: torná-lo judaico.

Um exemplo da transformação mencionada é o retorno do gueto ou dos bairros judaicos com alta densidade de judeus ortodoxos, bairros que funcionam, para quem mora nesses lugares, como uma "Pequena Jerusalém", isto é, como um espaço imbuído de certo nível de sacralidade. A alta concentração geográfica de grupos étnico-religiosos serve como base territorial para diversos objetivos. Assim, Shilhav (1989, p. 54) menciona as seguintes funções que a concentração territorial cria no caso dos bairros judaicos ortodoxos. Primeiro, existe uma função "defensiva", no sentido de que o grupo segregado pode dar continuidade ao seu estilo de vida. Em segundo lugar, encontramos uma função "preventiva", isto é, a criação de um nicho protetor que faz com que os membros se sintam seguros diante das pressões e falta de certezas encontradas no mundo exterior. Finalmente, o autor menciona a função relacionada ao "ataque", explicada como as possibilidades oferecidas pela área segregada como base para as atividades do grupo em sua luta com outros grupos étnicos ou sociais pelo controle de certas áreas urbanas. Desse modo, se da perspectiva material o território é naturalmente neutro, ele também tem uma dimensão ideológica que é usada pelos diferentes grupos étnico-religiosos para expressar 
valores e símbolos de sua cultura específica. Este processo é conhecido como territorialização (PÓVOA, 2010)².

No caso dos novos bairros judaicos, é importante esclarecer que se trata de uma segregação voluntária e não de uma segregação imposta como aquela que caracterizou grande parte de comunidades judaicas europeias na Idade Média. Bauman (2003) analisa em profundidade a criação de guetos voluntários em Modernidade líquida, a exemplo dos bairros fechados nos subúrbios ou dentro das próprias cidades. Segundo o sociólogo, a ideia central que orienta esses novos arranjos sociais é a procura por segurança que só é encontrada no convívio entre iguais. É por essa razão que Bauman destaca a mesmice como uma das características básicas das novas comunidades. Como decorrência desse traço, é possível referir-se ao componente de rejeição ao outro, ao diferente, típico dos bairros fechados. Em seu artigo "Que é o gueto? Construindo um conceito sociológico", texto no qual são analisados o gueto judaico medieval e guetos contemporâneos, tais como os guetos dos negros nos Estados Unidos ou favelas e villas miseria na Argentina, Wacquant (2004, p. 154) estabelece que o gueto constitui um dispositivo socio-organizador composto por quatro elementos: estigma, limite, confinamento espacial e encapsulamento institucional. O autor também destaca o aumento do intercâmbio social e cultural dentro do gueto como consequência do isolamento. Literalmente: "O gueto é o produto de uma dialética móvel e tensa entre a hostilidade externa e a afinidade interna que se expressa como uma ambivalência no nível do consciente coletivo" (WACQUANT, 2004, p. 159)3.

No que diz respeito aos bairros étnico-religiosos, é importante lembrar o papel protônico que na história tiveram os grandes templos e altares, a exemplo das catedrais, na conformação de cidades consideradas santas. Alguns autores, como Valins (2000, p. 574), salientam a importância do espaço sagrado na conformação de geografias da religião.

2 Nessa pesquisa, o autor descreve e analisa em detalhe o processo de territorialização do Bom Retiro, desde a chegada dos primeiros imigrantes judeus ao bairro.

3 É importante salientar que a tese de Wacquant se aplica de modo mais visível ao gueto judaico medieval e aos guetos impostos da atualidade, a exemplo das favelas. Porém, o autor trata ambos os arranjos socioespaciais como dois tipos ideais que expressam os extremos de um contínuo em que diferentes grupos sociais se situam, dependendo "da intensidade com que as forças do estigma, do limite, do confinamento espacial e da duplicação e completude institucional coalescem-se mutuamente e impõe-se sobre eles” (WACQUANT, 2004, p. 155). 
No antigo Israel, o Templo oficiava como o axis mundi, a quinta-essência do espaço sagrado, ao mesmo tempo em que desempenhava um papel fundamental como uma instância de institucionalização das ordens social e religiosa. Além dessa função central outorgada ao Templo, no Talmude encontramos uma classificação interessante do espaço que determina quais áreas devem ser consideradas públicas e quais, privadas. Em outras palavras, se bem é certo que o tempo e não o espaço foi a instância de sacralização mais importante no judaísmo, o espaço também recebeu a atenção dos sábios do Talmude no que diz respeito à existência de diferentes categorias de espaços organizados em um contínuo entre o sagrado e o profano.

Como fora mencionado, a partir da década de 1980 os judeus criaram novos modos de inserção na sociedade maior, entre eles, novas estratégias de territorialização. Além do mais, o padrão observado em diversas comunidades revela que, se no auge da Modernidade os judeus fizeram o possível para assimilarse à sociedade maior, rompendo as barreiras do gueto em todos os sentidos (espacial, social, cultural, linguístico e de diacríticos), na contemporaneidade observamos a criação de novos guetos judaicos nos quais seus habitantes fazem questão de distinguir-se da sociedade maior e de outros grupos. Os novos bairros ortodoxos encontrados em múltiplas cidades dos Estados Unidos, da Inglaterra, da França, do Brasil, da África do Sul, da Austrália e do Canadá se caracterizam pelo esforço de seus habitantes em construir barreiras simbólicas e institucionais que os separem do outro. É relevante para a presente análise a distinção que faz Wacquant (2004, p. 155) entre os bairros de imigrantes e os guetos, caracterizados por funções opostas. Assim, enquanto os primeiros atuam como um trampolim para a assimilação por meio "do aprendizado cultural e da mobilidade sócio cum espacial", os segundos constituem ilhas de isolamento material e simbólico direcionadas à desassimilação.

Os novos processos de territorialização ou de apropriação do espaço público entre os judeus são resultado da radicalização e aumento da ortodoxia judaica, por um lado; por outro, constituem fenômenos decorrentes da legitimação do multiculturalismo na atualidade e da procura ou renascimento de identidades particularistas no que é definido como sociedade pós-moderna. Entre os judeus, a expressão do particularismo étnico-religioso no nível espacial se expressa não só na criação e fortalecimento de bairros judaicos, transformando- 
os em novos guetos, mas, também, na ritualização do espaço público por meio das marcas judaicas com o qual ele é sinalizado. Esta estratégia é concretizada com a colocação de chanukiot em praças, shopping centers, estádios de futebol e avenidas, de outdoors informando aos vizinhos do bairro sobre eventos de diferentes tipos, como a celebração de festas do calendário judaico, a organização de viagens a Israel ou a vinda de rabinos famosos do exterior. Outro modo de judaização do espaço público é a existência de restaurantes, mercados e quitandas kosher, que são distinguidas como tais com grandes cartazes. No que diz respeito a São Paulo, a judaização do espaço público está afiançandose ao e atingindo novos alvos. Assim, por exemplo, no bairro de Higienópolis, o laboratório Fleury colocou há menos de um ano um cartaz informando aos seus usuários que a cafeteria é kosher.

Em algumas cidades, como em Buenos Aires, em 2012 foi colocada uma grande sucá em um ponto nevrálgico da cidade para a celebração pública da Festa dos Tabernáculos.

Os fenômenos mencionados - somados a outros que analisarei nas próximas páginas - constituem um claro indicador das mudanças pelas quais passaram as comunidades judaicas nas últimas décadas, e que apontam, inexoravelmente, para o renascimento do gueto judaico.

\section{"Nós" e "eles": o eruv e a dellmltação de um novo espaço judaico}

A judaização do espaço público em diferentes cidades da diáspora ganhou outra faceta nas últimas décadas: a criação de eruvim em cidades dos Estados Unidos, Canadá, Inglaterra e Austrália. Segundo pesquisas feitas nos últimos anos (VALINS, 2000, 2003; FONROBERT, 2005; SIEMIATYCKI, 2005, SMITH, 2007) na atualidade existem mais de 200 cidades com eruvim. O eruv é uma linha imaginária que cerca um determinado espaço, apesar de ter alguns itens que sinalizam sua existência (como pequenos cartazes em postes de energia, adesivos em árvores e/ou postes especialmente colocados para isso, lugares naturais como rios, lagos e montanhas). A ideia do eruv se relaciona com a $39^{\mathrm{a}}$ melachá relativa ao shabat, que proíbe carregar de um espaço privado para um espaço público, e vice-versa, objetos como bengalas, guarda-chuvas, bolsas, telefones celulares, etc., e pessoas, como crianças no colo ou em carrinhos, idosos 
em cadeiras de rodas e outros. A função do eruv é reclassificar o espaço público em espaço privado, permitindo que os judeus observantes não fiquem confinados em suas casas ao longo do shabat. Mas, se esta é a função do eruv do ponto de vista religioso, da perspectiva da construção, reformulação e sacralização do espaço, podemos ver nele um cerco que unifica ritualmente os residentes nessa área como se vivessem na mesma casa (VALINS, 2000, p. 581).

A construção de eruvim nas últimas décadas sinaliza uma forma de territorialização ou marcação do espaço público, tornando-o um espaço judaico, fenômeno que põe de manifesto algumas transformações no seio do judaísmo. A referência é ao aumento de ortodoxia nas cidades nas quais foram construídos eruvim, à sua segurança no que diz respeito à legitimidade do grupo para a realização dessas práticas e, paralela e curiosamente, à insegurança no que diz respeito a possíveis influências negativas que a sociedade maior pode exercer entre seus membros. Ao estabelecer uma fronteira construída culturalmente por um grupo específico para separar-se dos outros, o eruv revela a concepção que de si mesmos têm os judeus ortodoxos: moralmente superiores e puros, o que faz necessário erguer barreiras contra a sociedade maior definida como corrupta e impura (VALINS, 2003, p. 159). Não podemos nos esquecer de que, já na década de 1960, por meio da análise dos livros Levítico e Deuteronômio, Mary Douglas (1976) revelou como esses textos estão permeados pelo desejo de dividir o mundo em puro e impuro, sagrado e profano, e como a hibridez constitui a maior ameaça para a continuidade do judaísmo.

Da perspectiva dos estudos sobre o espaço, o eruv constitui uma combinação de espaço real e imaginado já que, como fora mencionado, os signos materiais para a sua construção muitas vezes são invisíveis, não só para os outsiders, mas, também, para os próprios insiders. Como consequência dessa sua característica, e como assinala Siemiatycki (2005, p. 260), para que o eruv funcione, é necessário do grupo um alto nível de imaginação e fé para reinterpretar o território expandido do eruv como espaço privado, como uma extensão do próprio lar.

Mas, apesar de o número de eruvim ter crescido exponencialmente nos últimos anos, nem todas as correntes judaicas aceitam a sua existência. Para alguns judeus seculares e para grupos reformistas contrários ao eruv nos Estados Unidos e na Inglaterra, a sua institucionalização faz lembrar o gueto medieval. 
A bibliografia sobre o tópico aponta as controvérsias suscitadas pelo estabelecimento do eruv em diferentes cidades, não só por parte de não judeus, mas também por parte de judeus neo-ortodoxos e reformistas. Assim, a responsa elaborada pelo Contemporary American Reform Responsa (CCAR), em 1983, contra a o estabelecimento de eruvim nos Estados Unidos é um claro indicador de que essa prática constitui um componente importante na identidade dos judeus ortodoxos, fenômeno que suscita conflitos e fere a visão do judaísmo de outras correntes. Eis um trecho do texto da responsa citada:

Será difícil debater com a ortodoxia e sua posição atual, que promove a separação e a estrita adesão ao que está escrito na Lei Judaica. Certamente nós, como judeus reformistas, que estamos interessados no espírito da Lei judaica, rejeitaríamos esse tipo de ficção legal para a observância do shabat, e devemos discutir esta questão com nossos colegas ortodoxos sobre a base desse espírito ${ }^{4}$.

O fato de o eruv ser uma construção e uma representação espacial pública da identidade judaica explica o fenômeno das múltiplas controvérsias em torno da sua criação na atualidade.

Para as correntes judaicas contrárias ao eruv, ele constitui uma reconfiguração espacial que questiona o universalismo do espaço público, os ideais do secularismo e a racionalidade da Modernidade (SUSMAN, 2010). Foi este o argumento principal utilizado diante do estabelecimento de eruvim em várias cidades da Inglaterra e dos Estados Unidos, em algumas das quais a questão foi resolvida nos tribunais (SIEMIATYCKI, 2005). Como faz questão de assinalar Lang Susman em relação às controvérsias suscitadas pelo estabelecimento de eruvim nos Estados Unidos:

4 A responsa da CCAR expressa a posição contrária do Movimento Reformista norte-americano à criação de eruvim nos Estados Unidos do seguinte modo: "It will be difficult to argue with the current Orthodox mood, which is one of further separation and strict adherence to the letter of the law. Certainly we, as Reform Jews, who are interested in the spirit of the law, would reject this kind of legal fiction for the observance of the shabbat, and we should discuss the matter in that spirit with our Orthodox colleagues". Disponível em: <http://data.ccarnet.org/cgi-bin/respdisp.pl?file=178\&year=carr $>$ 
Os dois lados do debate têm etiquetado o outro como irracional,caracterizando comoexecráveis as respectivas motivações de seus oponentes. É interessante que na medida em que o debate torna-se mais contencioso, os dois lados se distanciam dos argumentos legais em direção a uma linguagem da diferença, extremismo, inclusão e exclusão, insiders e outsiders, e, finalmente, chegam a visões opostas do que significa ser norteamericano. O eruv se transforma em um significante que se incrementa ressignificando continuamente os debates atuais sobre pluralismo, multiculturalismo e o lugar da religião na sociedade. (SUSMAN, 2010, p. 102)

No caso paulistano, a iniciativa da criação de um eruv no bairro dos Jardins ${ }^{5}$ foi de alguns rabinos ortodoxos que atenderam ao pedido de judeus observantes, os quais queriam ter na cidade um eruv como os que existem em Nova York, Londres e Antuérpia. A iniciativa ganhou ênfase quando um grande rabino israelense, especializado na halachá do eruv, visitou São Paulo e decidiu que, apesar do tamanho da cidade, é legal construir um eruv nela. Neste momento, os rabinos responsáveis por tal iniciativa estão negociando com a prefeitura as estratégias que serão utilizadas na construção do primeiro eruv brasileiro. Os detalhes técnicos, por definição complexos, também são alvo de discussão e precisam da autorização do governo local. Assim, por exemplo, no caso de São Paulo, os postes de energia não poderão ser utilizados por questões haláchicas, o que torna necessário a colocação de postes especiais para sinalizar o futuro eruv. Quando perguntei ao rabino mentor da ideia se não há receios pelo fato de a cidade sofrer continuamente diferentes tipos de vandalismos, a resposta foi positiva. Mesmo assim, o eruv será construído. À outra pergunta, o rabino respondeu negativamente: a Federação Israelita do Estado de São Paulo (Fisesp) não foi consultada a respeito da criação do eruv em São 
Paulo, acrescentando, ironicamente, que talvez seja uma boa ideia fazê-lo. O fato de que a Fisesp não tenha sido consultada sobre um assunto que tem despertado controvérsias ríspidas entre diferentes correntes judaicas em outros contextos nacionais, pareceria ser um indício de que o setor ortodoxo sente-se seguro e suficientemente forte, e que prefere negociar com possíveis grupos contrários ao eruv depois dele ter sido construído.

É razoável prognosticar que, uma vez estabelecido o eruv no bairro dos Jardins, o preços dos imóveis se eleve significativamente, já que muitos ortodoxos desejarão morar num bairro no qual será mais fácil respeitar o shabat. Como decorrência desse anseio é possível imaginar que a população ortodoxa dos Jardins aumente de forma significativa.

Perguntei ao rabino mencionado se não há receios de que os não judeus vejam no eruv um modo de os judeus se separarem da sociedade maior. A resposta foi taxativa: nós somos diferentes e eles já sabem que somos diferentes.

\section{Os novos espaços judaicos da comunidade paulistana: algumas hipóteses}

Parece-me que na presente conjuntura existe uma superposição e uma inovação no que diz respeito aos espaços judaicos considerados significativos para a comunidade judaica paulistana, além de o espaço público ter se transformado num espaço no qual é importante deixar uma marca. Assim, se bem que não encontremos na cidade um nível de judaização desses bairros como o que existe em Crown Heigths ${ }^{6}$, ainda assim observa-se uma revalorização da diáspora e uma reterritorialização dela. Esta nova concepção de diáspora, segundo Godschmidt (2000, p. 85-7), se traduz numa diáspora muito diferente daquela idealizada pelos irmãos Boyarin (1993), concebida como uma consciência coletiva de compartilhamento do espaço da diáspora com outros grupos. O caráter exclusivista dos adeptos do Chabad em Nova York - semelhante ao que temos observado entre os grupos ortodoxos em São Paulo, com a iniciativa de construir um eruv - contradiz a diáspora ideal dos teóricos das diásporas contemporâneas que salientam seus traços híbri-

6 Bairro de Nova York com grande concentração de judeus ortodoxos, onde se encontra a casa do Sétimo Rebbe de Lubavitch, alvo de peregrinação não só de membros do movimento Chabad-Lubavitch, mas, também, de judeus religiosos e seculares. 
dos, intersticiais, polifônicos e sincréticos (BOYARIN; BOYARIN, 1993; CLIFFORD, 1994).

Se a isto acrescentarmos a importância que o lar próprio tem para alguns membros da comunidade ${ }^{7}$ o renascimento dos lugares de origem na consciência dos atores sociais, como as diferentes cidades e schtetls da Europa Central e Oriental, e certas cidades do Oriente Médio ${ }^{8}$, o quadro é bastante complexo e remete a uma hierarquização de espaços judaicos ou espaços sagrados em lugar da clássica dicotomia entre Eretz Israel, ou o Estado de Israel, versus o exílio ou a diáspora. É minha hipótese que nesta conjuntura histórica existe um deslocamento do centro, provavelmente por diferentes tipos de saturação, que desemboca em uma policentralidade de espaços judaicos ou de espaços sagrados para o judaísmo.

O lar judaico', que ganhou na atualidade relevância como referente identitário importante para diferentes segmentos da comunidade judaica paulistana, provavelmente seja um efeito de um processo maior conhecido como a privatização da religião. Este fenômeno se expressa entre os grupos moderados das diferentes religiões, ao tempo que suas versões fundamentalistas tentam conquistar a cena e o cenário públicos.

Nesse contexto, parece-me interessante - e irônico - lembrar a famosa frase de Gordon para explicar a assimilação falha dos judeus na Europa do século XIX que exigia deles: "Heié adam betzeitecha vihudí beohalecha" (ser judio no lar e um homem na rua). Diante dessa cisão da identidade judaica, a única solução para os sionistas foi a criação de um Estado judeu soberano em Terras de Israel. Hoje, entretanto, as estratégias de apropriação de espaços públicos em São Paulo e em outras diásporas, como a volta do gueto ortodoxo, a colocação de chanukiot em espaços públicos durante a festa de Chanuká e a criação de eruvim permitem aos judeus construir um espaço público à sua imagem e semelhança e desenvolver uma identidade judaica "total", princípio expresso

7 Dados colhidos no trabalho de campo revelam que os dois rabinos da Congregação Israelita Paulista (CIP) e a esposa de um dos rabinos apontaram o lar como o espaço judaico mais importante para eles. O mesmo ocorre com um significativo número de membros e frequentadores da CIP.

8 Nos últimos anos, grupos de judeus organizam viagens à procura das suas raízes na Europa Central e Oriental, em Rhodes, Turquia e outros países dos quais seus pais ou avós partiram para estabelecer-se no Brasil.

9 Não devemos esquecer que é no lar que grande parte dos rituais judaicos são celebrados. 
na frase citada de Gordon um século antes. Não foram poucas as vezes que ouvi de diferentes interlocutores ortodoxos "olha só a quantidade de ofertas que temos em educação judaica, recreação e comida kosher. Antes não era assim, antes só se via isso em Israel”. De fato, o mercado kosher tem crescido e se diversificado consideravelmente nos últimos anos, facilitando a vida dos judeus ortodoxos paulistanos (GERLADO, 2010).

Finalmente, gostaria de chamar a atenção ao caminho de mão dupla percorrido pela ortodoxia. Assim, se por um lado ela se retrai em bairros étnicos e instituições cada vez mais exclusivistas, separando-se dos judeus não ortodoxos e da população maior, por outro, faz questão de judaizar um espaço público como nunca antes foi cogitado por segmentos mais liberais da comunidade judaica paulistana. Diante desses novos fenômenos, muitas perguntas ainda precisam de uma resposta. Assim, por exemplo, é possível esboçar o seguinte interrogante: o que acontece com os paulistanos não judeus que decodificam o símbolo da chanukiá a partir de um horizonte cultural brasileiro, altamente identificado com as correntes evangélicas que também a utilizam em seus cultos?

De algum modo, o eruv e a chanukiá remetem a uma prática cuja característica principal não é física, mas discursiva. Paralelamente, é importante destacar que as fronteiras são essenciais na definição de espaços, os espaços transformam-se em lugares de identidade, e as identidades em fluxo continuamente revisam suas fronteiras concretas e conceituais. Voltando ao eruv, podemos concluir que as comunidades moldam o espaço e são moldadas por ele por meio da sinalização de limites. Por último, acredito que seja possível afirmar que por intermédio dos numerosos discursos em relação a seus limites e os espaços que cerca, além das posições contrárias a seu estabelecimento, o eruv apresenta não menos poder no espaço urbano que as muralhas ou barreiras concretas dos guetos medievais. 


\section{Referências}

BAUMAN, Zygmunt. Comunidade: a busca por segurança no mundo atual. Rio de Janeiro: Zahar Ed., 2003.

BOYARIN, Daniel; BOYARIN, Jonathan. Diaspora: Generation and the Ground of Jewish Identity. Critical Inquiry, n. 19, 1993.

CLIFFORD, James. Diasporas. Cultural Anthropology, v. 9, n. 3, p. 302-338, 1994.

FONROBERT, Charlotte. The political symbolism of the Eruv. Jewish Social Studies. v. 11, n. 3 , 2005.

GERLADO, Clésio. Mercado Kasher em São Paulo. Dissertação (Mestrado em Língua Hebraica, Literatura e Cultura Judaicas). Universidade de São Paulo, 2010.

GODSCHMIDT, Henry. Crown Heights is the Center of the World: Reterritorializing a Jewish Diaspora. Diaspora, v. 9, n. 1, p. 83-106, 2000.

SUSMAN, Alexandra Lang. Strings attached: an analysis of the eruv under the religion clauses of the first amendment and the religious land use and institutionalized persons act. Journal of Race, Religion, Gender and Class. v. 9, n. 1, p. 93-134, 2010.

PÓVOA, Carlos Alberto. A territorialização dos judeus na cidade de São Paulo. São Paulo: Humanitas, 2010.

SHILHAV, Yosseph. The Haredi Guetto: the theology behind the geography. Contemporary Jewry. v. 10, n. 2, p. 51-64, 1989.

SMITH, B. "On Place and Space: The Ontology of the Eruv" in Barry Smith, Preprint version of a paper to appear in C. Kanzian (ed.), Cultures: Conflict-Analysis-Dialog, Frankfurt: Ontos Verlag, 2007.

VALINS, Oliver. Institucionalised religion: sacred texts and Jewish spatial practice. Geoforum. v. 31, n. 4, p. 575-586, nov. 2000.

Stubborn identities and the construction of socio-spatial boundaries: ultra-orthodox Jews living in contemporary Britain. Transactions of the Institute of British Geographers New Series. v. 28, n. 2, p. 158-175, jun. 2003.

WACQUANT, Loïc. Que é o gueto? Construindo um conceito sociológico. Revista de Sociologia Política, n. 23, p. 155-164, nov. 2004. 